\title{
Prevalence of intestinal parasitic infections among patients attending in a tertiary care hospital of eastern region of Nepal - A retrospective, laboratory based study
}

\author{
Ratna Baral ${ }^{1}$, Pramod Jha ${ }^{2}$, Ritu Amatya ${ }^{3}$, Basudha Khanal ${ }^{4}$ \\ ${ }^{1}$ Associate Professor, Department of Microbiology, B. P Koirala Institute of Health Sciences, Ghopa, Dharan, ${ }^{3}$ Associate \\ Professor, Department of Microbiology, Nepal Medical College, Jorpati, Kathmandu, ${ }^{4}$ Professor and Head, Department \\ of Microbiology, B. P Koirala Institute of Health Sciences, Ghopa, Dharan, Nepal, ${ }^{2}$ Medical Laboratory Technologist, \\ National University of Natural Medicine, Oregon, USA
}

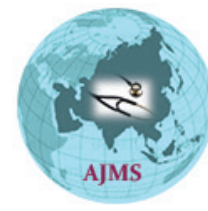

A B S T R A C T

Background: Intestinal parasitosis still constitutes one of the major causes of public health problems in the world, particularly in developing countries. Nepal is a small, impoverished country prevalent to infectious diseases, including intestinal parasitosis. Poverty, lack of awareness, failure to practice proper hand washing after defecation, practice of open defecation, unsafe drinking water and use of improper toilets are some of the reasons causing of parasitic infections. Aims and Objective: To determine the types of intestinal parasites in stool samples of patients attending to hospital. Materials and Methods: Stools specimens collected in standard stool vial were submitted in microbiology (2006-2010) unit at BP Koirala Institute of Health Sciences hospital (BPKIHS) were examined for intestinal parasites by direct wet mount using normal saline $(0.9 \%)$ and lugol's iodine $(0.5 \%)$. Results: A total of 11,791 stool samples (2928 in 2006, 2238 in 2007, 2151 in 2008, 2344 in 2009 and 2130 in 2010) were submitted to the Parasitology section of Department of Microbiology BPKIHS were included in the analysis. Of these, $675(5.72 \%)$ were positive intestinal protozoa and $289(2.45 \%)$ for intestinal helminths. Giardia intestinalis accounted for the most prevalent parasitic infection (3.34\%) followed by Entamoeba histolytica/E. dispar (1.96\%) and Hookworm $(0.97 \%)$. A parasitic infection was observed to be highest among 20-50 years of age group and lowest in the less than 5 years group of subjects. Conclusion: Intestinal parasitosis is a common problem. Amoebiasis, giardiasis and the common intestinal helminthes Ascaris lumbricoides, hookworm, and Trichuris trichiura were prevalent in our settings.

Key words: Stool, Intestinal parasites, Poverty, BPKIHS

\section{Access this article online}

Website:

http://nepjol.info/index.php/AJMS DOI: 10.3126/ajms.v8i3.16909 E-ISSN: 2091-0576 P-ISSN: $2467-9100$

\section{INTRODUCTION}

Intestinal parasitic infections are amongst the most common infections worldwide but are more prevalent in developing countries ${ }^{1}$, including Nepal. These infections are distributed throughout the World, with high prevalence in low socioeconomic communities in the tropic and subtropics with temperate climates. ${ }^{2}$ World Health Organization estimates that some 3.5 billion people worldwide are affected, and that 450 million are sick as a result of these infections, the majority being children. ${ }^{3}$
The parasites are important aetiological agents of gastrointestinal disorders such as diarrhoea, dysentery, vomiting, lack of appetite, abdominal distension and sometimes mentally related disorders. ${ }^{4,5}$ Furthermore, chronic infections with Ascaris lumbricoides and hookworms (Ancylostoma duodenale or Necator americanus) may cause malnutrition and anaemia in high risk groups. ${ }^{6-8}$

Intestinal parasitic infections are highly endemic in populations with low socio-economic status, overcrowding, poor hygiene, favorable warm and humid conditions for 
the transmission of the parasites, limited access to potable water supply, waste disposal, malnutrition, lack of adequate healthcare facilities and peasant farming, favoring larval skin penetration and oral-faecal transmission. ${ }^{9,10}$ These factors are the cause of major proportion of burden of the disease and death in developing countries. ${ }^{10}$

Microscopic analysis of feces is a common laboratory diagnostic test used for screening of parasites in resource limited settings.

Nepal is one of the countries where there is lack of sanitation, lack of access to potable water and improper hygiene which favor the survival of intestinal parasites. In Eastern Nepal, there is insufficient information on the magnitude of parasitic infection among cases attended at a tertiary hospital. The information generated from this study may provide the initial information needed for planning reminiscent public health control measures. Moreover, differentiation of parasitic agents is an important step for initiation of deliberate treatment and prevention strategies. Therefore, the present retrospective study was conducted to determine the species and prevalence of human intestinal parasites among patients attended at B.P.Koirala Institute of Health Sciences Dharan, Nepal during a five year time period.

\section{MATERIAL AND METHODS}

A retrospective study was carried out in the Department of Microbiology for a period of five years (2006 to 2010), 11,791 patients with symptoms suggestive of parasitic infections coming to our tertiary care Hospital for whom stool examination for parasites was requested by physicians were included in the study. The patients were provided with wide mouthed clean, dry, properly labeled glass container for collection of samples and recommended 5grams of solid or $10 \mathrm{ml}$ of liquid stool to be collected. The stool specimens were routinely examined using direct wet mount (saline) and iodine wet mount preparation to detect protozoal tropozoites, helminth eggs or larvae and parasitic cysts by trained medical microbiologist and the results were recorded in the Parasitology laboratory register book \& computerbased laboratory software (Q-Lab). For the purpose of this study, all such complete records were extracted and the results for helminths eggs, larvae and protozoan cyst or trophozoite infections were analyzed using SPSS version 20.0.

\section{RESULTS}

A total of 11,791 stool samples (2928 in 2006, 2238 in 2007, 2151 in 2008, 2344 in 2009 and 2130 in 2010) were submitted to the Parasitology section of Department of Microbiology BPKIHS were included in the analysis. Of these, $675(5.72 \%)$ were positive for intestinal protozoa and $289(2.45 \%)$ for intestinal helminths.

Giardia lamblia accounted for the most prevalent parasitic infection (3.34\%) followed by Entamoeba histolytica/E. dispar $(1.96 \%)$. Among helminthes, hookworm (Ancylostoma duodenale or Necator americanus) contributed most with the prevalence of $1.32 \%$, followed by Ascaris lumbricoides $0.45 \%$, Hymenolepis nana $0.2 \%$ Strongyloides stercoralis $0.18 \%$, Trichuiris tricbiuria, Taenia sp. $0.1 \%$ and Enterobius vermicularis $0.05 \%$ as depicted in Table 1.

Mixed infection with either protozoan and protozoan or protozoan and helminth was found in 17 stool samples as shown in Table 2.

There is no significant gender difference in prevalence of parasitic infection though males predominate $(8.4 \%)$ as shown in Table 3.

The prevalence of parasitic infections was observed to be highest among 20-50 years of age group and lowest in the less than 5 years group of subjects which is demonstrated in Table 4.

\section{DISCUSSION}

Parasitic infestations of the gastrointestinal tract are one of the most common infections worldwide. It has been estimated that some 3.5 billion people are affected, and 450 million are sick as a result of these infections. ${ }^{11}$ The rate of infection is remarkably high in Sub-Saharan Africa, where the majority of HIV/AIDS cases do occur. ${ }^{12}$ The incidence of intestinal parasitic infections is $50 \%$ in developed world, whereas it reaches up to $95 \%$ in developing countries. Both protozoa and helminthes are responsible for these infections with diarrhea being the primary clinical manifestation. ${ }^{13}$

The present retrospective study revealed that the overall prevalence of intestinal parasitic infestation in our set up is $8.17 \%$. This finding is consistent with the findings of the studies done in Saudi Arabia, Ethiopia and Iran. ${ }^{14-16}$ Inconsistent with this finding, there are several studies conducted round the globe which has shown higher prevalence of parasitic infestation. For example, in a study in rural southern India, the overall period prevalence of intestinal parasites was $97.4 \%$ per month ${ }^{17}$ and in another study in Sierra Leone showed a prevalence rate of $73.5 \%$. The higher rates in these communities may be attributed to improper hygiene and agricultural backgrounds. ${ }^{18}$

Among the protozoans, Giardia lamblia (3.34\%) and Entamoeba bistolytica $(1.96 \%)$ were the most common in our study participants which is similar to the study conducted in 
Table 1: Prevalence (\%) of helminth and protozoan infections, Feb 2006-Jan 2010

\begin{tabular}{|c|c|c|c|c|c|c|}
\hline \multirow{3}{*}{$\begin{array}{l}\text { Total sample } \\
\text { parasite } \\
\text { protozoan infections }\end{array}$} & \multicolumn{5}{|c|}{ Years of study (\%) } & \multirow{3}{*}{$\begin{array}{c}\text { Overall } \\
\text { prevalence }\end{array}$} \\
\hline & 2006 & 2007 & 2008 & 2009 & 2010 & \\
\hline & 2928 & 2238 & 2151 & 2344 & 2130 & \\
\hline E. histolytica/E. dispar & $14(0.47)$ & $20(0.89)$ & $36(1.67)$ & $76(3.24)$ & $85(3.99)$ & $231(1.96)$ \\
\hline Giardia Lamblia & $101(3.44)$ & $75(3.35)$ & $85(3.95)$ & $69(2.94)$ & $64(3.0)$ & $394(3.34)$ \\
\hline Entamoeba coli & $3(0.1)$ & $9(0.4)$ & $10(0.46)$ & $9(0.38)$ & $2(0.09)$ & $33(0.28)$ \\
\hline Trichomonas hominis & 0 & $1(0.4)$ & $2(0.09)$ & $3(0.12)$ & $2(0.09)$ & $8(0.07)$ \\
\hline Isospora belli & 0 & $1(0.04)$ & 0 & 0 & 0 & $1(0.008)$ \\
\hline Cyclospora cayetanensis & 0 & $1(0.04)$ & 0 & 0 & 0 & $1(0.008)$ \\
\hline Cryptosporidium parvum & 0 & 0 & 0 & $1(0.04)$ & 0 & $1(0.008)$ \\
\hline Balantidium coli & 0 & $1(0.04)$ & 0 & 0 & 0 & $1(0.008)$ \\
\hline Blastocystis & 0 & $1(0.04)$ & 0 & 0 & 0 & $1(0.008)$ \\
\hline \multicolumn{6}{|l|}{ Overall prevalence of Protozoans } & $675(5.72)$ \\
\hline \multicolumn{7}{|l|}{ Helminthic Infections } \\
\hline Hookworm & $14(0.47)$ & $24(1.07)$ & $36(1.67)$ & $41(1.74)$ & $40(1.87)$ & $156(1.33)$ \\
\hline Hymenolepis nana & $9(0.30)$ & $5(0.22)$ & 0 & $5(0.21)$ & $5(0.23)$ & $24(0.20)$ \\
\hline Strongloides stercoralis & $1(0.03)$ & $3(0.13)$ & $5(0.23)$ & $8(0.34)$ & $4(0.18)$ & $21(0.18)$ \\
\hline Trichuris trichiuria & $1(0.03)$ & $2(0.08)$ & $1(0.04)$ & $11(0.46)$ & $2(0.09)$ & $17(0.14)$ \\
\hline Tinea spp & $2(0.06)$ & $2(0.08)$ & 0 & 0 & $8(0.37)$ & $12(0.10)$ \\
\hline Enterobius vermicularis & $3(0.10)$ & $1(0.04)$ & 0 & $2(0.08)$ & 0 & $6(0.05)$ \\
\hline Overall prevalence of helminths & & & & & & $289(2.45)$ \\
\hline Over all prevalence of parasitic infections & & & & & & $964(8.17)$ \\
\hline
\end{tabular}

\begin{tabular}{|c|c|c|c|c|c|}
\hline Parasites & 2006 & 2007 & 2008 & 2009 & 2010 \\
\hline G.lamblia+E.histolytica & 1 & - & 2 & 4 & \\
\hline Taenia Spp+Hook worm & 1 & - & - & - & - \\
\hline G.lamblia+Hook worm & - & - & 2 & - & - \\
\hline T. trichuria+Hook worm & - & - & - & 4 & - \\
\hline G.lamblia+Round worm & - & - & - & 2 & - \\
\hline E.histolytica+T.trichuria & - & - & - & 1 & - \\
\hline
\end{tabular}

\begin{tabular}{|c|c|c|c|}
\hline Parasite & Males (\%) & Females (\%) & $\begin{array}{c}\text { Overall } \\
\text { prevalence (\%) }\end{array}$ \\
\hline E. histolytica/E. dispar & $113(1.82)$ & $118(4.13)$ & $231(1.96)$ \\
\hline Giardia Lamblia & $243(3.91)$ & $151(2.70)$ & $394(3.34)$ \\
\hline Entamoeba coli & $15(0.24)$ & $18(0.32)$ & $33(0.28)$ \\
\hline Trichomonas hominis & $5(0.08)$ & $3(0.05)$ & $8(0.07)$ \\
\hline lodamoeba buetschlii & $2(0.03)$ & $2(0.03)$ & $4(0.03)$ \\
\hline Total & $378(6.08)$ & $292(7.23)$ & $670(5.68)$ \\
\hline Hookworm & $71(1.14)$ & $84(1.50)$ & $115(0.97)$ \\
\hline Ascaris lumbricoides & $22(0.35)$ & $31(0.55)$ & $53(0.45)$ \\
\hline Hymenolepis nana & $13(0.20)$ & $11(0.19)$ & $24(0.20)$ \\
\hline $\begin{array}{l}\text { Strongloides } \\
\text { stercoralis }\end{array}$ & $13(0.20)$ & $8(0.14)$ & $21(0.18)$ \\
\hline Trichuris trichiuria & $10(0.16)$ & $7(0.12)$ & $17(0.14)$ \\
\hline Tinea spp & $7(0.11)$ & $5(0.08)$ & $12(0.10)$ \\
\hline $\begin{array}{l}\text { Enterobius } \\
\text { vermicularis }\end{array}$ & $3(0.04)$ & $3(0.05)$ & $6(0.05)$ \\
\hline Total & $139(2.20)$ & $149(2.63)$ & $288(2.09)$ \\
\hline
\end{tabular}

this institute itself by Gyawali $\mathrm{N}$ et al in $2010 .{ }^{19}$ Comparable findings were reported from different tropical countries. ${ }^{20-22}$
The prevalence of intestinal helminthes observed in this study, confirm that intestinal helminthiasis, mainly hookworm infection, are prevalent among patients attending B.P.Koirala Institute of Health sciences, Dharan Nepal. Other previous studies have also reported a high prevalence of hookworm infections than other geohelminths in Nepal. ${ }^{23-26}$ The higher prevalence of hookworm infections has previously been reported in other rural tropical areas of low socio-economic status. This comparative high prevalence observed in our study is likely to be associated with poor hygienic conditions and low socio-economic status of the population of eastern Nepal visiting this tertiary care center.

In contrary, some studies have shown that Ascaris lumbricoides to be the most common helminth in Nepal ${ }^{27-29}$ which is the second most common helminthes found in our study. Some researchers have demonstrated Trichuris trichiuria to be most prevalent helminthes. ${ }^{30,31}$ The reason for this difference could be the different geographical areas surveyed for analysis.

On the other hand, the prevalence of other helminths, Hymenolepis nana, Strongloides stercoralis, Trichuris trichiuria, Tinea spp, Enterobius vermicularis were very low. The low prevalence of these parasites is likely to be influenced by the ecological factors.

Regarding distribution of the intestinal parasites among various age groups, more infection rate was observed in the age group of 20-50 years through the years 2006 to 2010 followed by age groups $6-19$ years, and was lowest among individuals with extremes of ages which is in contrast 


\begin{tabular}{|c|c|c|c|c|}
\hline \multirow{2}{*}{$\begin{array}{l}\text { Type of Infection } \\
\text { Parasite }\end{array}$} & \multicolumn{4}{|c|}{ Age groups (Years) } \\
\hline & $\leq 5$ & $6-19$ & $20-50$ & $\geq 50$ \\
\hline E. histolytica/E. dispar & 29 & 43 & 110 & 49 \\
\hline Giardia Lamblia & 60 & 133 & 170 & 31 \\
\hline Entamoeba coli & 4 & 9 & 20 & 6 \\
\hline Trichomonas hominis & 0 & 2 & 4 & 2 \\
\hline lodamoeba buetschlii & 1 & 0 & 1 & 2 \\
\hline Isospora belli & 0 & 0 & 1 & 0 \\
\hline Cyclospora cayetanensis & 0 & 0 & 1 & 0 \\
\hline Cryptosporidium parvum & 0 & 1 & 0 & 0 \\
\hline Balantidium coli & 0 & 1 & 0 & 0 \\
\hline Blastocystis & 0 & 1 & 0 & 0 \\
\hline Total & 94 & 190 & 307 & 90 \\
\hline \multicolumn{5}{|l|}{ Helminthic Infections } \\
\hline Hookworm & 2 & 19 & 95 & 41 \\
\hline Ascaris lumbricoides & 3 & 14 & 30 & 10 \\
\hline Hymenolepis nana & 5 & 10 & 8 & 2 \\
\hline Strongloides stercoralis & 0 & 4 & 12 & 5 \\
\hline Trichuris trichiuria & 0 & 4 & 9 & 4 \\
\hline Tinea spp & 1 & 1 & 7 & 3 \\
\hline Enterobius vermicularis & 1 & 3 & 2 & 0 \\
\hline Total & 12 & 55 & 163 & 65 \\
\hline
\end{tabular}

with the previous findings ${ }^{32-34}$ where as a very recent study from Ethiopia has also shown high parasitic infectivity in individuals aged 15 years and above. ${ }^{14}$ The reason for the higher prevalence of the infection among individuals aged 19 years and above is their frequent exposure to the environment as majority of them are bread-winner of the family and they strive for their livelihood and by doing so they do various types of works including farming, sewage cleaning etc and they eat and drink improper food and water during their job that make them vulnerable to infection.

Our study revealed higher rate of infection in males than in females $(5.68 \%$ vs $2.09 \%$ ) which is similar to findings of other studies on general population in Nepal and in other Southeast Asian countries. ${ }^{32,33,35-38}$ Such sex predominance in infections rates is likely to be a reflection of different behaviour between the two groups. ${ }^{8,39}$

\section{Limitations}

Incompleteness of the parasitology stool examination record may have led to the underestimation of the overall and individual parasite prevalence rates among patients visiting B.P.Koirala Institute of Health Sciences Dharan during last five years (2006-2010). The use of wet mount techniques for stool examination in this study may lead to the lack of detection of certain parasites that demand other concentration techniques for their identification.

\section{CONCLUSION}

The present study revealed that the prevalence of parasitic infections among patients attending B. P. Koirala Institute of
Health Sciences Dharan, Nepal is comparatively low. Among intestinal parasites, Giardia lamblia, Entamoeba histolytica and Hookworm were found to be the most prevalent during the past five years (2006-2010). Although the retrospective data of the present study showed mixed figure for the prevalence of most of the intestinal parasites, there was an increasing trend for some intestinal parasites like E. histolytica, Hookworm and Ascaris lumbricoides throughout the past five years.

Although it seems that the overall burden of parasites is low, the increasing trend of some parasites in the community indicates the failure of maintaining good sanitation, personal hygiene, provision of safe drinking water, health education etc.

Therefore, we hope this piece of information may provide invaluable statistics needed for planning meaningful public control programmes that aim at reducing the prevalence and morbidity of parasitic infections.

\section{ACKNOWLEDGEMENT}

We thank the laboratory staff and faculty, Department of Microbiology BPKIHS, Dharan for their contribution.

\section{REFERENCES}

1. Araj GF, Musharrafieh UM, Haydar A, Ghawi A, Itani R and Saliba R. Trends and prevalence of intestinal parasites at a tertiary care center in Lebanon over a decade. J Med Liban 2011; 59 (3): 143-148.

2. Norhayati M, Fatmah MS, Yusof $S$ and Edariah $A B$. Intestinal parasitic infections in Man: A review. Med J Malaysia 2003; 58 (2):296-305.

3. Bdri S and Adwen G. Prevalence of intestinal parasitic infections in Jenin Governorate, Palestine: a 10- year retrospective study. Asian Pacific J Trop Medicine 2010; 3(9): 745-747.

4. Lynee Shore, Garcia. Diagnostic Medical Parasitology. Intestinal Nematodes. $4^{\text {th }}$ ed. ASM Press, Washington D.C. 2004:250-271

5. Bethony J, Brooker S, Albanico M, Geiger M, Loukas A, Diemert D and Hotez J. Soil-transmitted helminth infections; Ascaris, Trichuriasis and hookworm. Lancet. 2006; 367(9521):1521-1532.

6. Albonico M, Stoltzfus RJ, Savioli L, Tielsch JM, Chwaya HM, et al. G. Epidemiological evidence for a differential effect of hookworm species, Ancylostoma duodenale or Necator americanus, on iron status of children. Int J Epidemiol 1998; 27(3):530-537.

7. Awasthi HS, Bundy DAP and Lorenzo Savioli L. Helminthic infections. BMJ 2003; 327:431-433.

8. Hotez PJ, Bundy DAP, Beegle $\mathrm{K}$, et al. Helminth Infections: Soil-transmitted Helminth Infections and Schistosomiasis. In: Jamison DT, Breman JG, Measham AR, et al., editors. Disease Control Priorities in Developing Countries. $2^{\text {nd }}$ edition. Washington (DC): World Bank; 2006. Chapter 24. Available from: http://www.ncbi.nlm.nih.gov/books/NBK11748

9. Hailemariam G, Kassu A, Abebe G, Abate E, Damte D, Mekonnen $E$, et al. Intestinal parasitic infections in HIVIAIDS and HIV seronegative individuals in a teaching hospital, Ethiopia. Jpn J 
Infect Dis 2004;57(2):41-43.

10. Mazigo D, Ambrose E, Zinga M, Bahemana E, Mnyone L, Kweka J, et al. Prevalence of intestinal parasitic infections among patients attending Bugando Medical Centre in Mwanza, north-western Tanzania. Tanzan J Health Res 2010; 12(3): 1-7.

11. WHO, Control of Tropical Diseases, WHO, Geneva, Switzerland, 1998.

12. UNAIDS, UNAIDS/WHO HIV Epidemic Update, Geneva, Switzerland, 2002.

13. E. Chacon-Cruz. Intestinal protozoal diseases, Medicine Journal.2003; 3 (5):1-11.

14. Zaglool DAM, Khodari YAW, Gazzaz JZ, Dhafar OK, ShakerASH, et al. Prevalence of Intestinal Parasites among Patients of Al-Noor Specialist Hospital, Makkah, Saudi Arabia. Oman Med J 2011; 26(3): 182-185.

15. Bayissa Chala. A Retrospective Analysis of the Results of a Five-Year (2005-2009) Parasitological Examination for Common Intestinal Parasites from Bale-Robe Health Center, Robe Town, South-eastern Ethiopia. ISRN Parasitology 2013; 694731:1-7.

16. Arani AS, Alaghehbandan R, Akhlaghi L, Shahi M and Lari AR. Prevalence of intestinal parasites in a population in south of Tehran, Iran. Rev Inst Med Trop Sao Paulo 2008; 50(3):145-149.

17. Kang G, Mathew MS, Rajan DP, Daniel JD, Mathan MM, Mathan VI, et al. Prevalence of intestinal parasites in rural Southern Indians. Trop Med Int Health 1998; 3(1):70-75.

18. Gbakima AA and Sah FD. Intestinal parasitic infections among rural farming communities in eastern Sierra Leone. Afr J Med Sci 1995; 24(2):195-200.

19. Gyawali N, Amatya R and Nepal HP. Intestinal parasitosis in school going children of Dharan municipality, Nepal. Trop Gastroenterol 2009; 30(3):145-147.

20. Fernandez MC, Verghese S, Bhuvaneswari R, Elizabeth SJ, Mathew T, Anitha A, et al.A comparative study of the intestinal parasites prevalent among children living in rural and urban settings in and around Chennai. J Commun Dis 2002; 34(1):35-39.

21. Mumtaz $\mathrm{S}$, Siddiqui $\mathrm{H}$ and Ashfaq $\mathrm{T}$. Frequency and risk factors for intestinal parasitic infection in children under five years age at a tertiary care hospital in Karachi. J Pak Med Assoc 2009; 59(4):216-219.

22. Nkrumah B and Nguah SB. Giardia lamblia: a major parasitic cause of childhood diarrhoea in patients attending a district hospital in Ghana.Parasites and Vectors 2011;4 (163):1-7.

23. Yong ST, Sim S, LeeJ, Ohrr H, Kim HM and Kim H. A smallscale survey on the status of intestinal parasite infections in rural villages in Nepal. The Korean Journal of Parasitology 2000; 38(4):275-277.

24. Navitsky RC, Dreyfuss ML, Shrestha J, Khatry SK, Stoltzfus RJ and Albonico M. Ancylostoma duodenale is responsible for hookworm infections among pregnant women in the rural plains of Nepal. J Parasitol 1998; 84(3):647-651.

25. Estevez EG, Levine JA and Warren J. Intestinal parasites in a remote village in Nepal. J Clin Microbiol1983; 17(1): 160-161.

26. Kurup $R$ and Hunjan GS. Intestinal parasites in St Lucia: a retrospective, laboratory-based study. J Rural Trop Public Health 2010; 9:24-30

27. Rai SK, Kubo T, Nakanishi M, et al. Status of soil-transmitted helminthic infection in Nepal. J Jpn Assoc Infect Dis 1994; 68(5): 625-630.

28. Rai SK, Hirai K, Ohno $Y$ and Matsumura T. Village health and sanitary profile from eastern hilly region, Nepal. Kobe J Med Sci 1997; 43(3-4): 121-133.

29. Rai SK, Nakanishi M, Upadhyay MP, Rai CK, Hirai K, Ohno Y, et al. Effect of intestinal helminth infection on some nutritional parameters among rural villagers in Nepal. Kobe $\mathrm{J}$ Med Sci 1998; 44(2):91-98.

30. Sharma BK, Rai SK, Rai DR and Choudhury DR. Prevalence of intestinal parasitic infestation in school children in the northeastern part of Kathmandu valley, Nepal. Southeast Asian J Trop Med Public Health 2004; 35(3):501-505.

31. Shrestha A, Rai SK, Basnyat SR, Rai CK and Shakya B. Soil transmitted helminthiasis in Kathmandu, Nepal. Nepal Med Coll J 2007; 9(3):166-169.

32. Shakya B, Bhargava D, Shrestha $S$ and Rijal BP. Intestional parasitosis. J Inst Med (Nepal). 2009; 31:13-16.

33. Ishiyama S, Rai SK, Ono K and Uga S. Small scale study on intestinal parasitosis in a remote hilly village in Nepal. NepalMed Coll J 2003; 5(1):28-30.

34. Khanal KL, Rai SK, Khanal PR and Ghimire G. Status of intestinal parasitosis among hospital visiting patients in Deukhury Valley, Dang, Nepal. Nepal Med Coll J 2011; 13(2): 100-102.

35. Rai SK, Matsumara T, Ono K, et al. Intestinal parasitosis in an "unknown disease outbreak" hit rural hilly area in western Nepal. Nepal Med Coll J 2000; 2:61- 64.

36. Sinniah B and Rajeswar B. Economic status associated with intestinal nematode infections. In: collected papers on the control of soil transmitted helminthes: Asian Parasite Control Organization 1998: 71-77.

37. Bansal D, Sehgal R, Bhatti HS, Shrivastava SK, Khurana S, Mahajan RC, et al. Intestinal parasites and intra familial incidence in a low socio - economic area of Chandigarh (North India). Nepal Med Coll J 2004; 6(1): 28-31.

38. Uga S, Hoa NT, Noda S, Moji K, Cong L, Aoki Y, et al. Parasite egg contamination of vegetables from a suburban market in Hanoi, Vietnam. Nepal Med Coll J 2009; 11(2): 75-78.

39. Albonico M, Chwaya HM, Montresor A, Stolfzfus RJ, Tielsch JM, et al. Parasitic infections in Pemba island schoolchildren. East Afr Med J 1997; 74(5):294-298

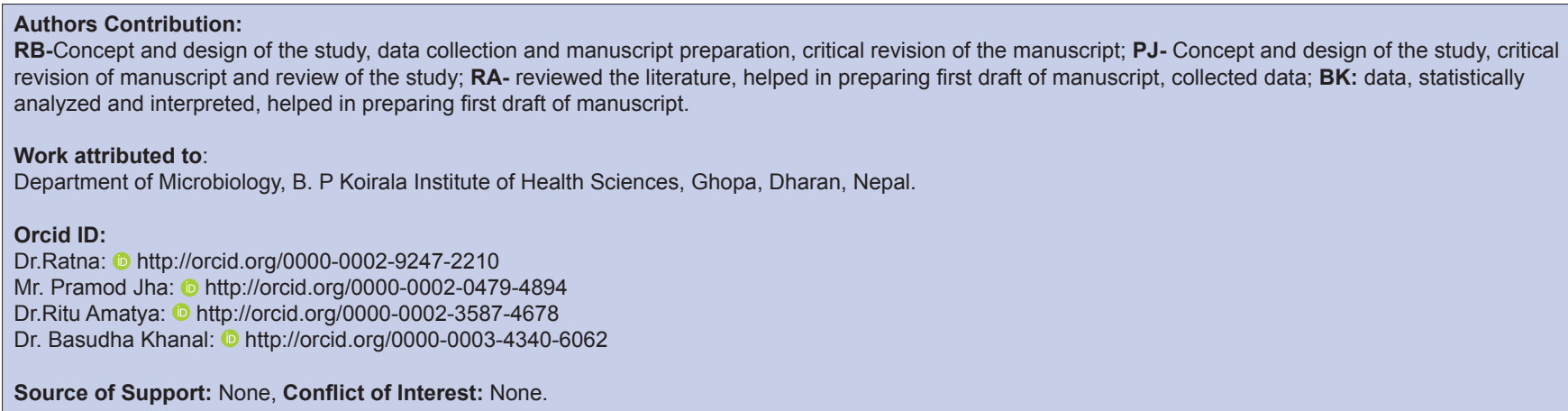

